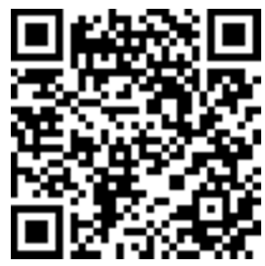

$\bar{I} Q \bar{A} N-$ Vol: 02, Issue: 03, Dec 2019

DOI: 10.36755/iqan.v2i03.105 PP: 39-54

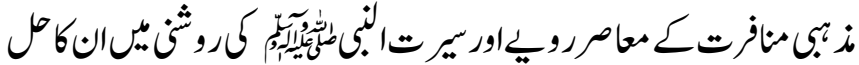 \\ Contemporary Trends of Religious Hatred and Solution in the light \\ of Seerat Al-Nabi \\ *Hafiz Abdul Razzaq \\ Assistant professor, Department of Islamic Studies, \\ Govt. postgraduate college, Samundri, Faisalabad, Pakistan. \\ **Muhammad Asif \\ Lecturer, Department of Islamic Studies, \\ Govt. postgraduate college, Bahawalnagar, Pakistan \\ ***Dr. Hafiz Amjad Hussain \\ Associate Professor, Department of Islamic Studies, \\ Govt. postgraduate college, Samundari, Faisalabad, Pakistan.
}

\title{
VERSION OF RECORD
}

\section{Received: 17-Aug-19 Accepted: 12-Nov-19}

Online/Print: 31-Dec-19

\begin{abstract}
$\underline{\text { Abstract }}$
Contemporary Trends of Religious Hatred and its Solution in the Light of Seerat Tayyibah. It is necessary to establish internal and external peace and to abolish disintegration for a healthy society. Without peace any society can become the center of sedition, disintegration, hatred and deterioration. Its inhabitants will lose their peace. The Holy Prophet (SAW) preaching was common to each age, area, color and creed and is paragon for each of them. The nation constantly takes benefits from this very Holy teaching. Religious and sectarian hatred occurs when the opposite opinion is not entertained, to ignore the others' emotions, to enforce ones opinion over others and to be harsh in sub issues. The present research paper will highlight the solutions of these issues and sub issues. The nation constantly takes benefits from this very Holy teaching. Religious and sectarian hatred occurs when the opposite opinion is not entertained, to ignore the others' emotions, to enforce ones opinion over others and to be harsh in sub issues. The present research paper will highlight the solutions of these issues.
\end{abstract}

Keywords: Religious Hatred, Seerat, Disintegration, Sectarianism, Fundamentalism. To Cite this Article:

Razzaq, A., Asif, M., \& Hussain, D. H. A. (2019). URDU: مذببى منافرت ع معاصر رويِ اور

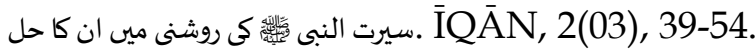




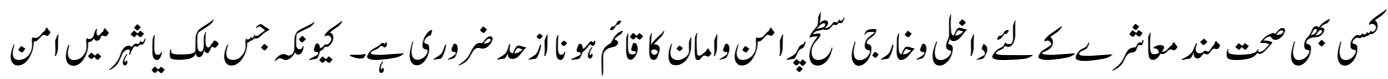

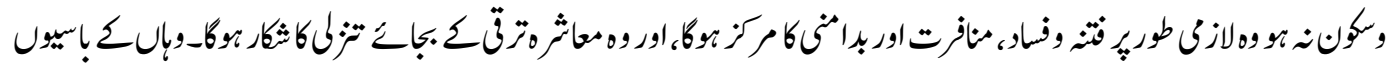

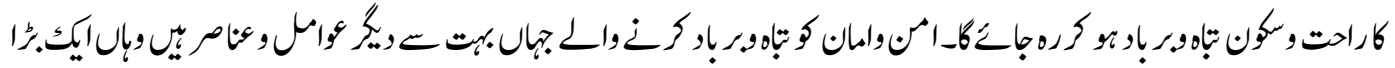

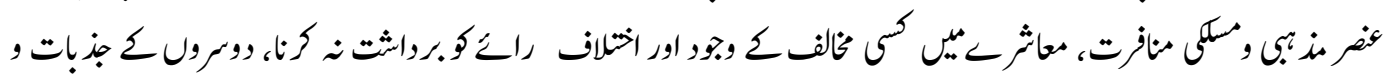

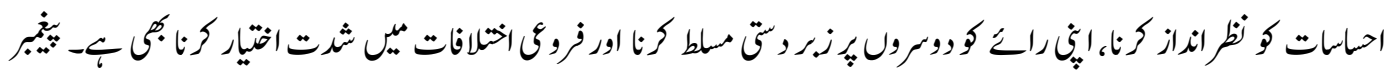

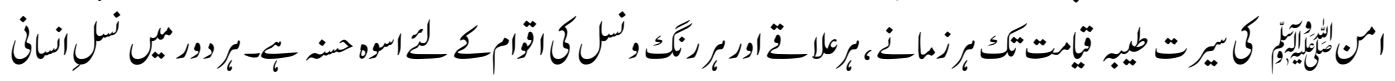

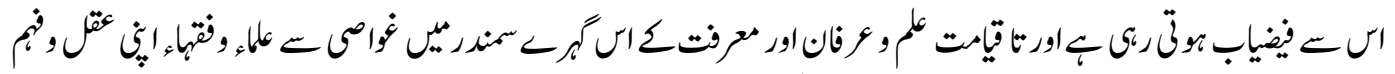

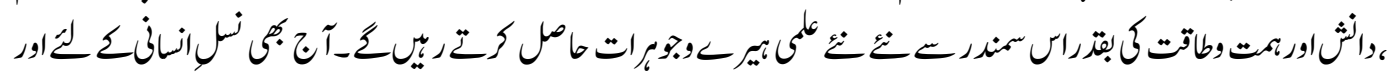

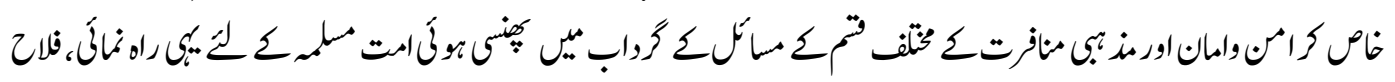

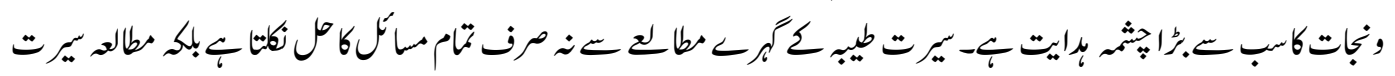

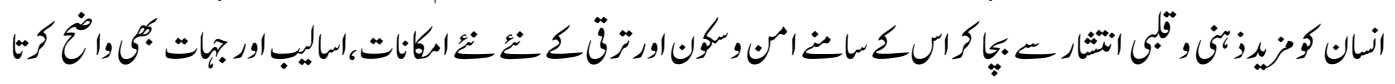

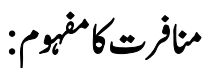

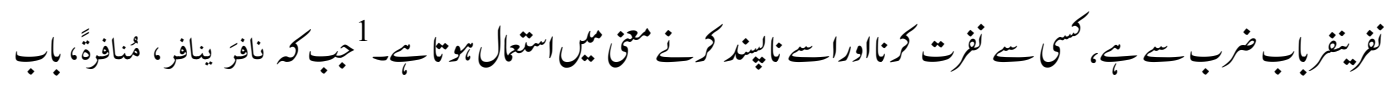

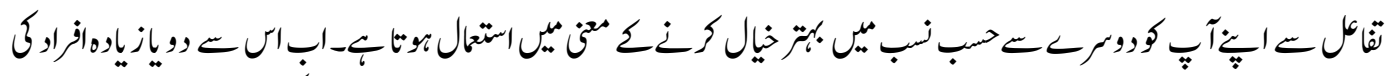

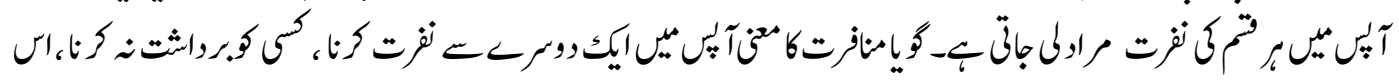

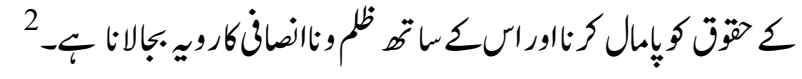

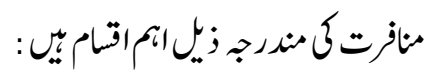

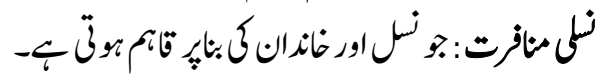

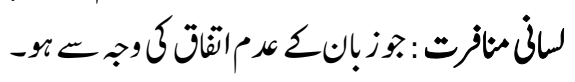

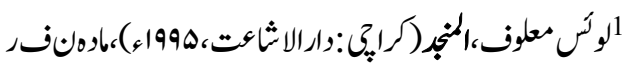

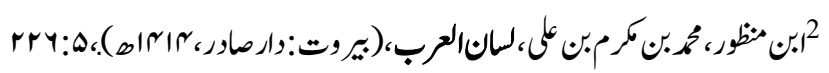




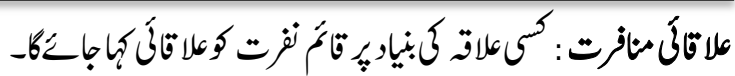

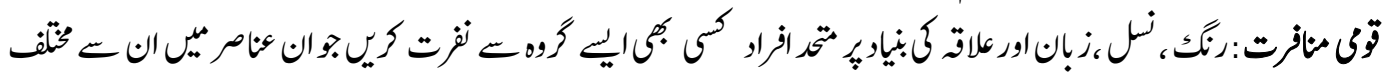

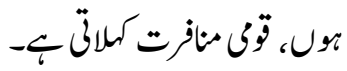

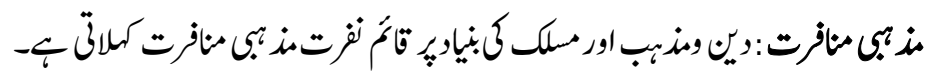

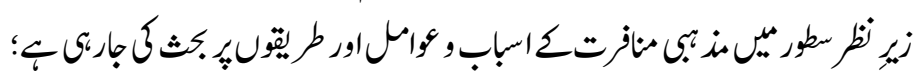

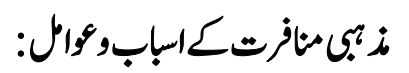

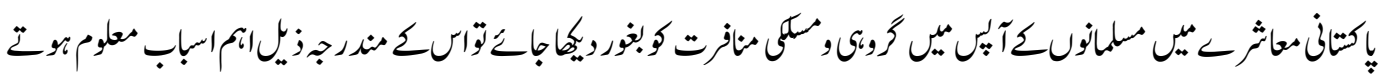

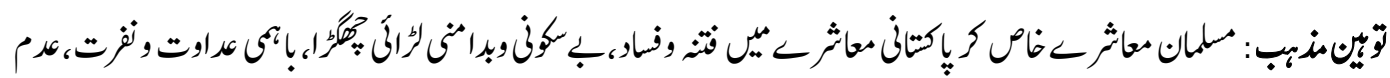

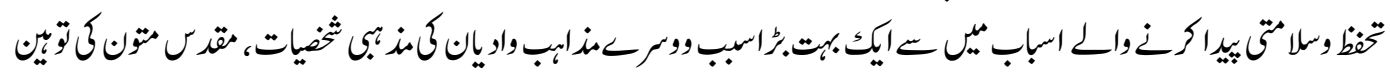

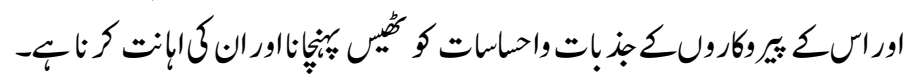

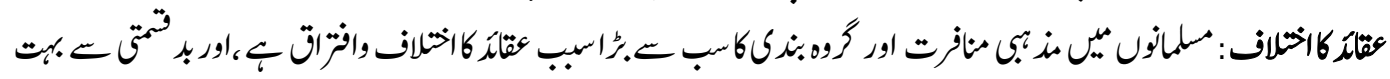

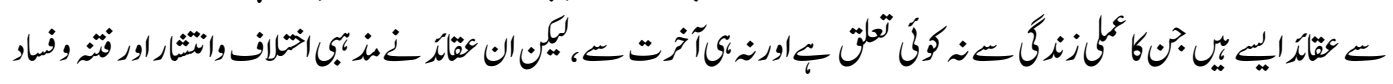
象

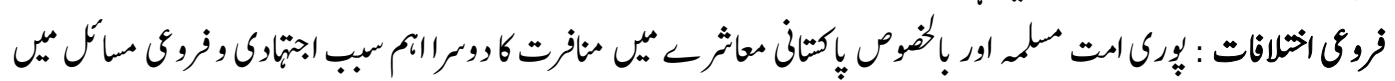

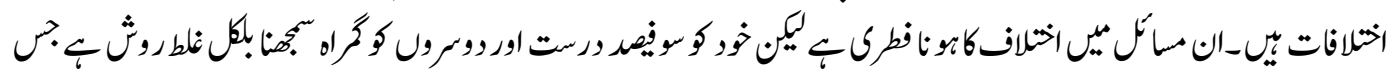

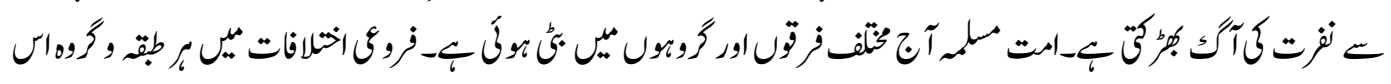

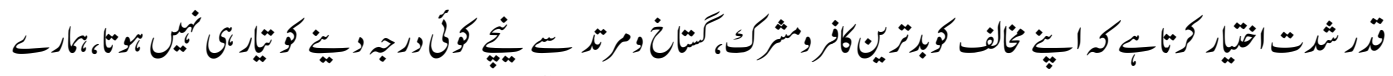

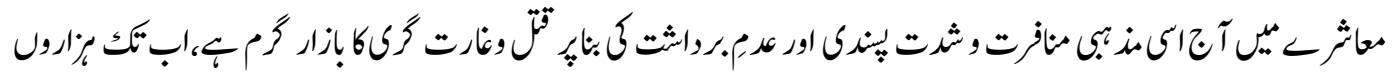

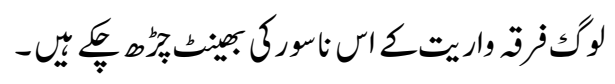

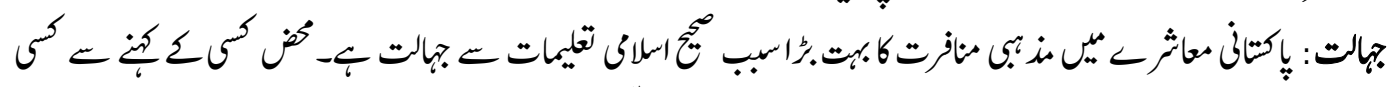

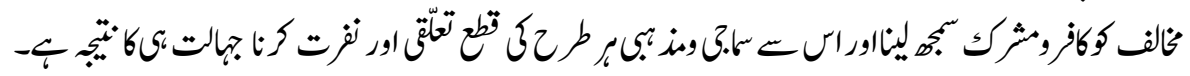

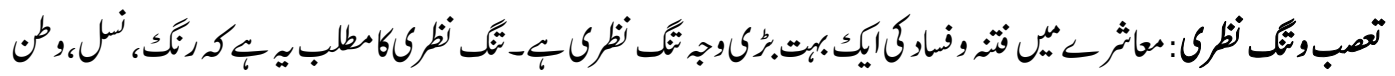

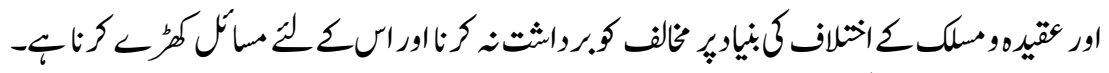

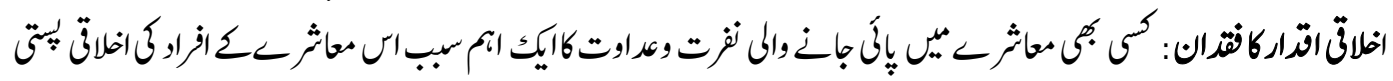

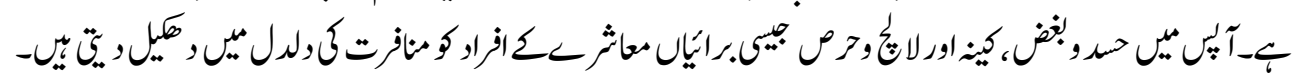




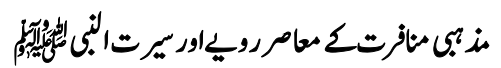

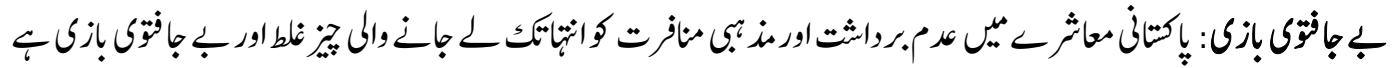

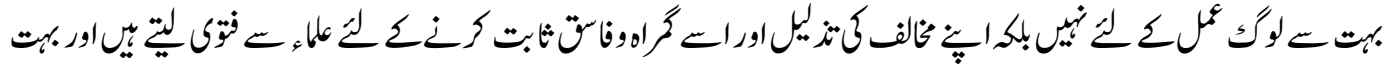

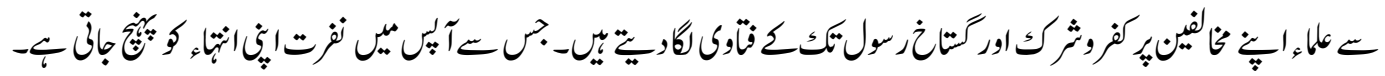

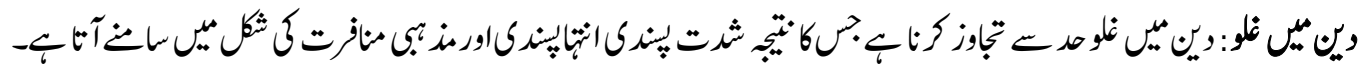

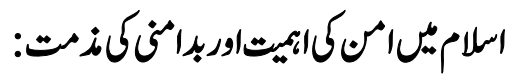

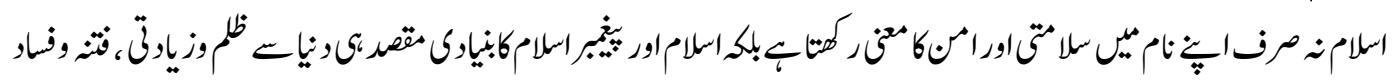

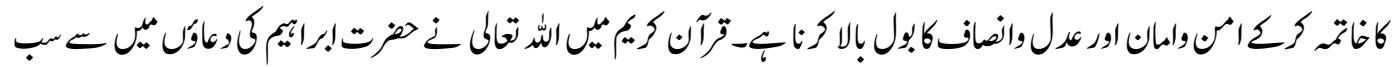

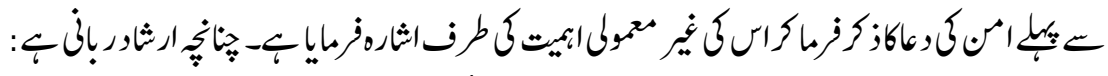

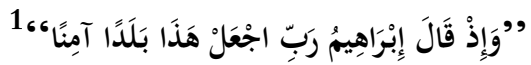

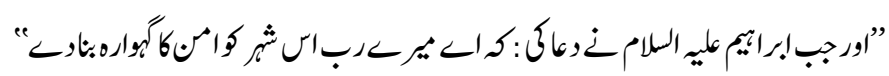

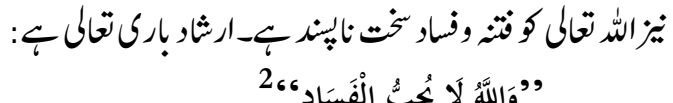

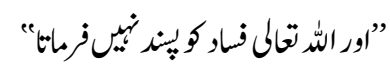

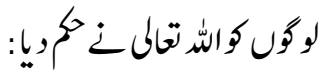

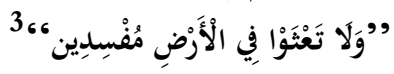

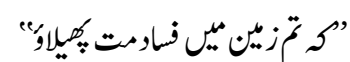

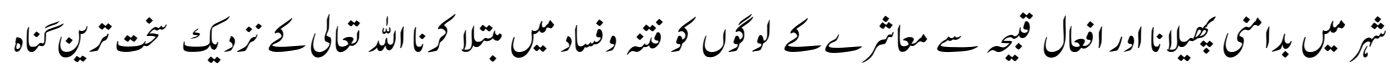

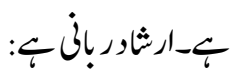

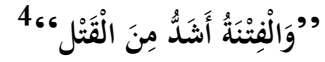

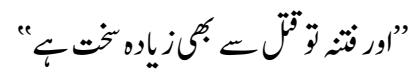




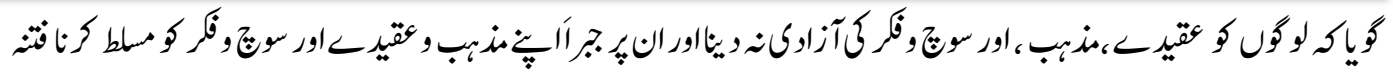

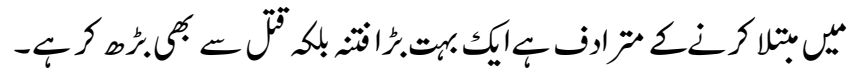

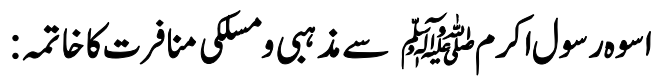

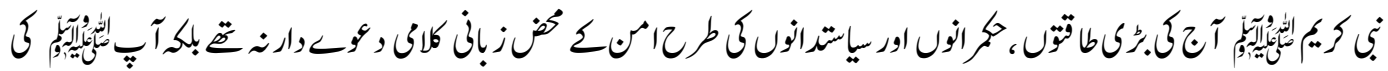

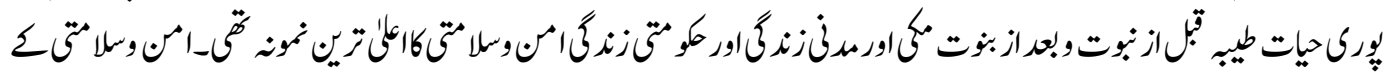

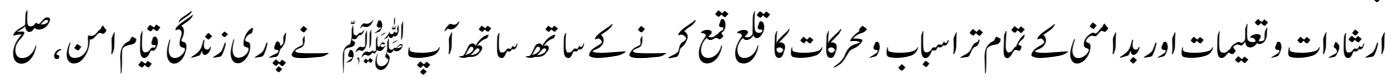

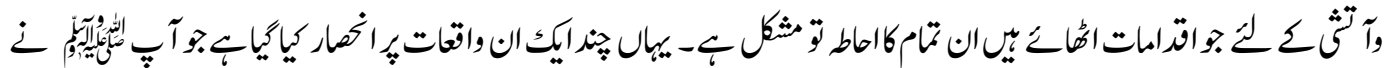

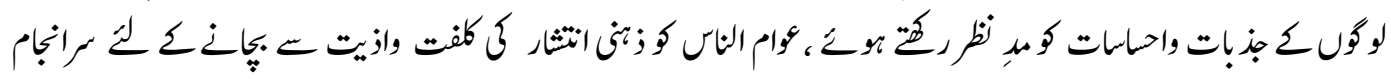

$-\ddot{E} \leqslant$

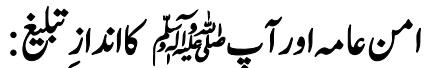

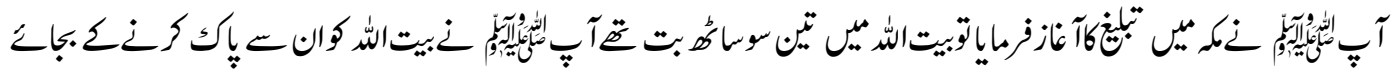

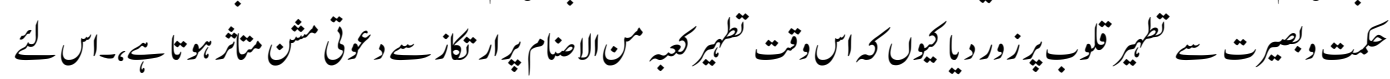

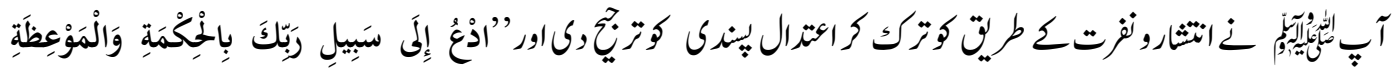

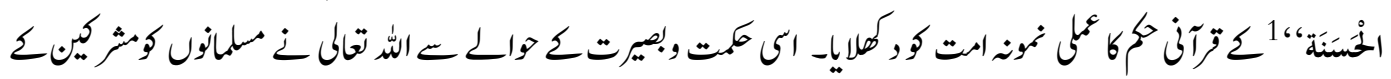

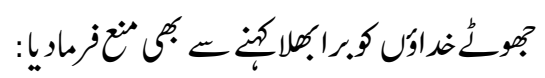

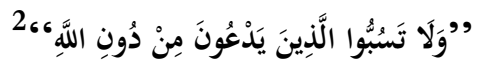

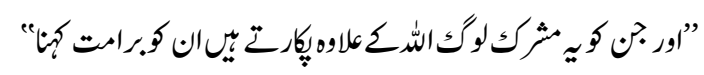

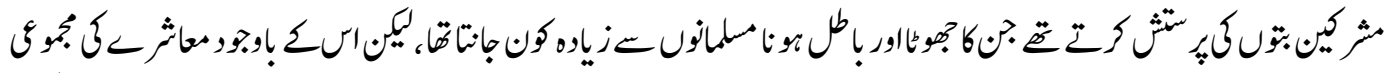

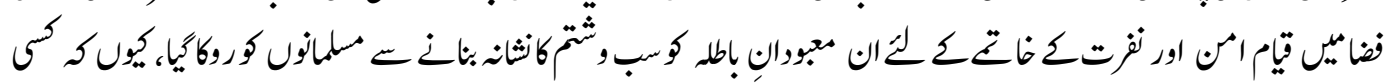

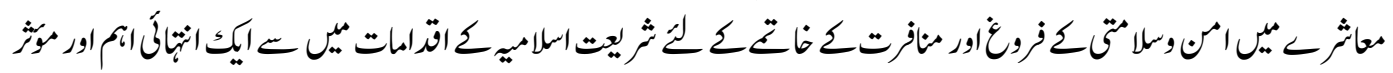

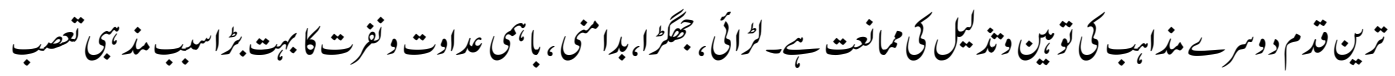

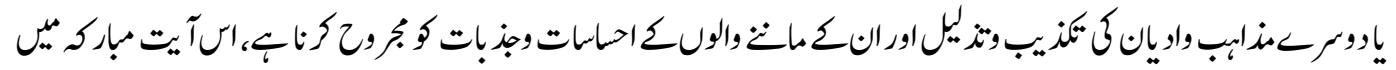

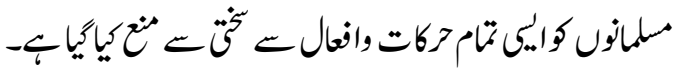




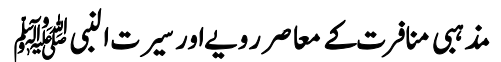

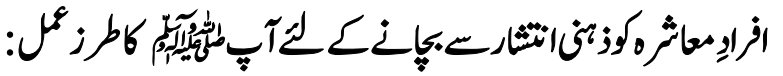

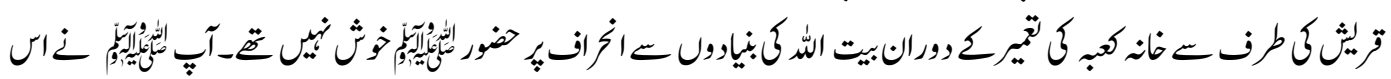

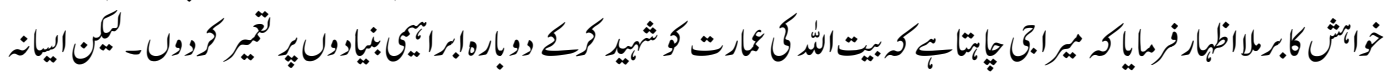

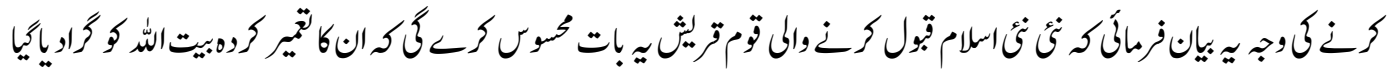

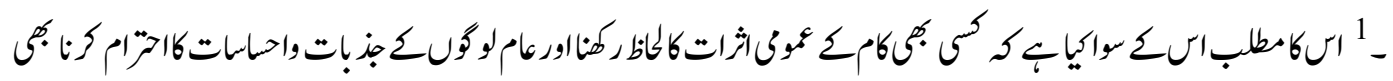

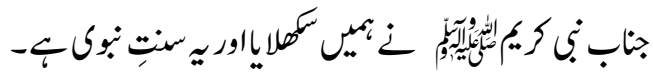
婴

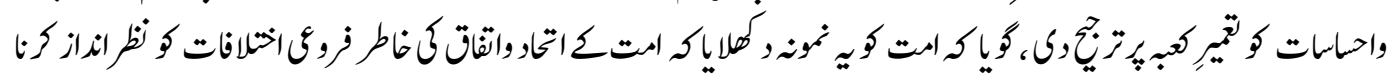

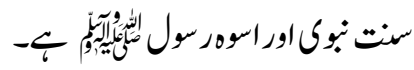

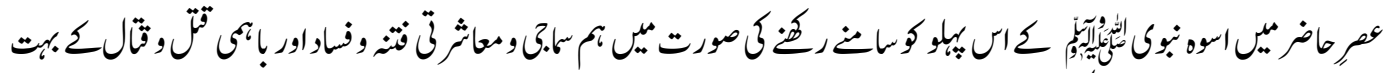

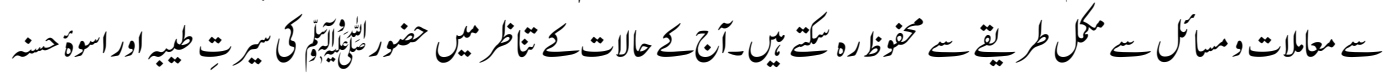

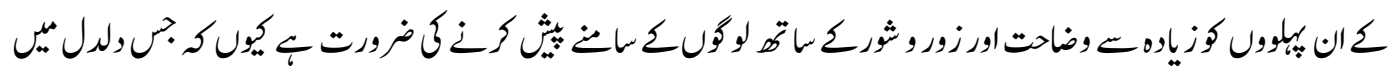
-

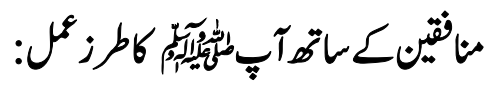

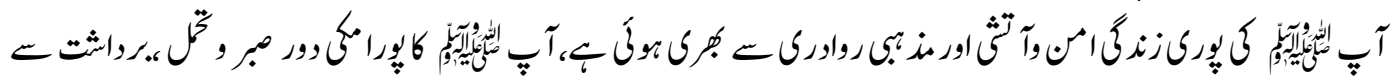

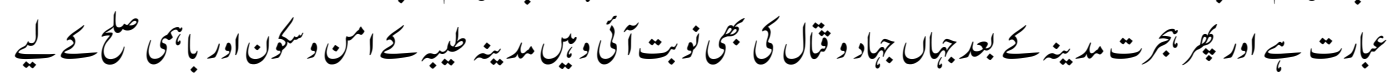

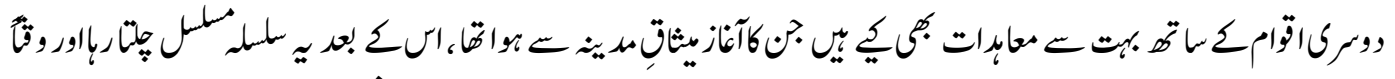

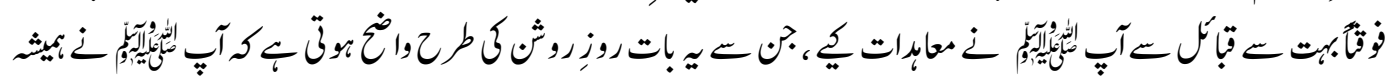

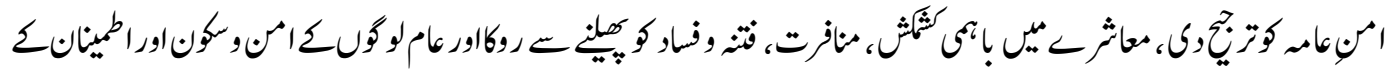
年

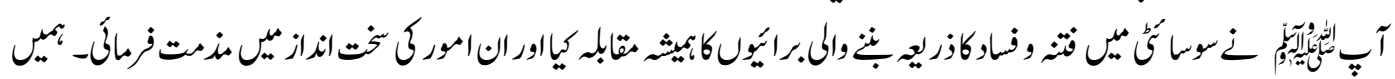

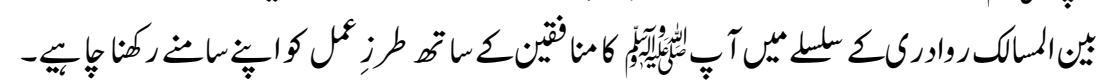

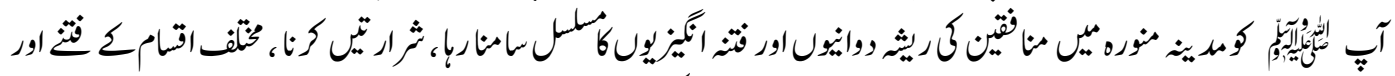

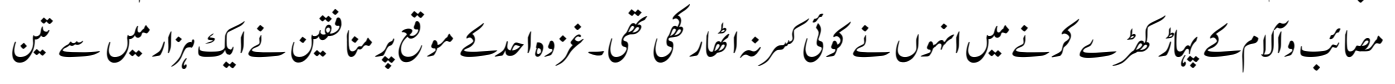

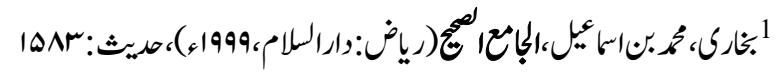




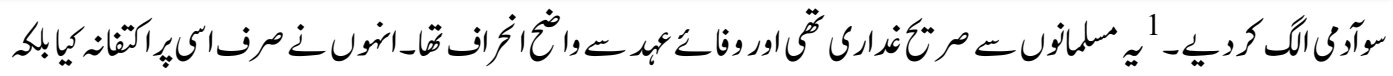

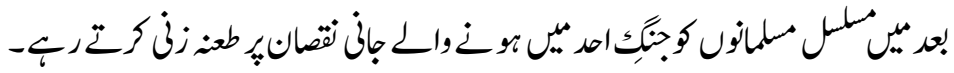

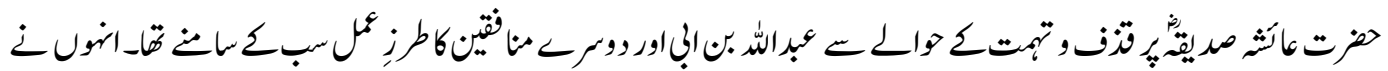

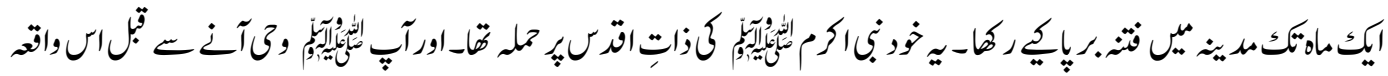

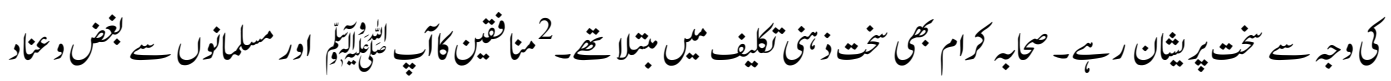

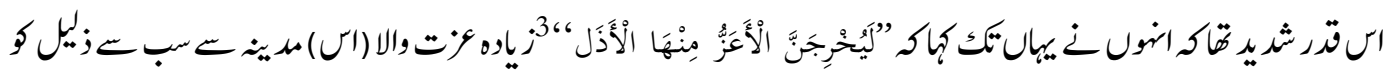
4⿺辶⿸丆口

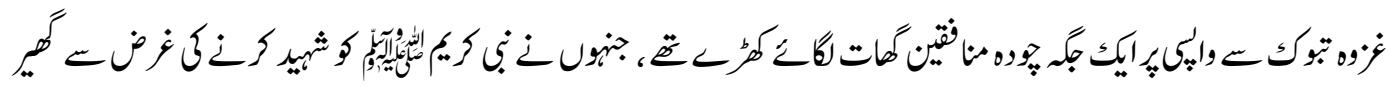

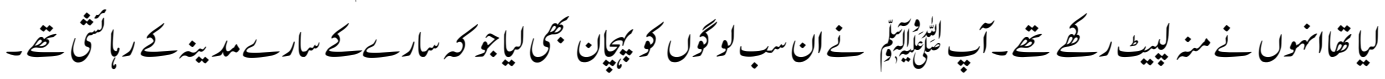

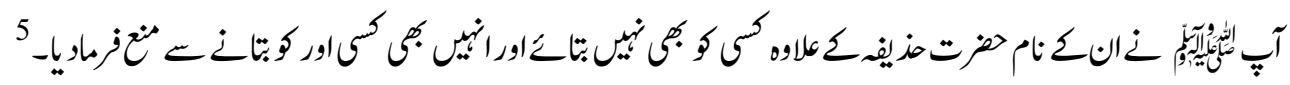

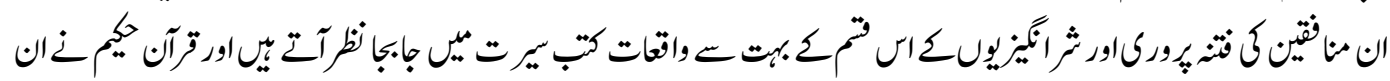

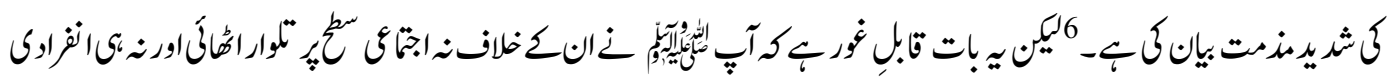

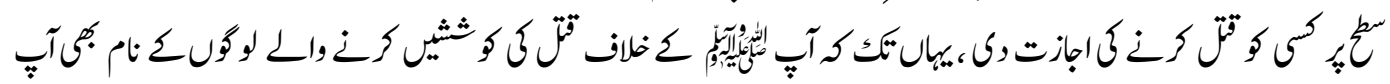

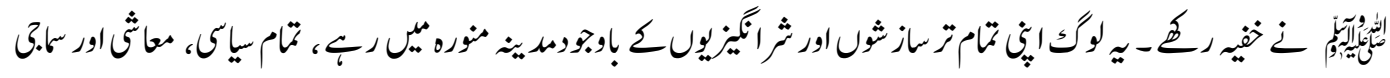

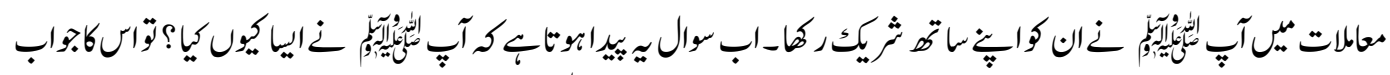

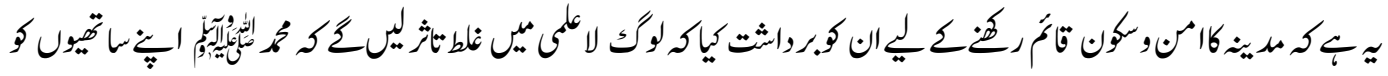
تز

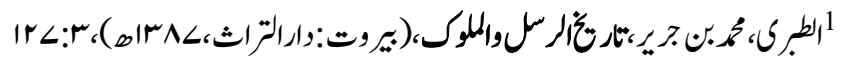

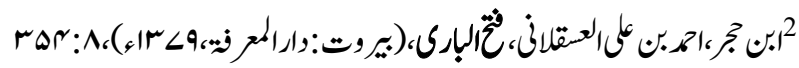

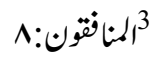

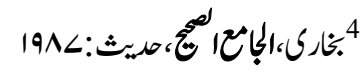

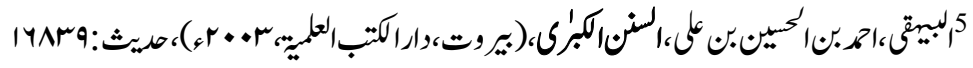
9: 9

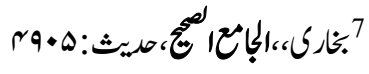




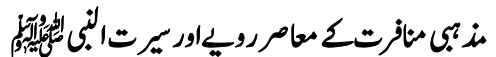

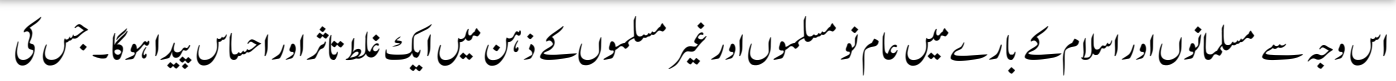

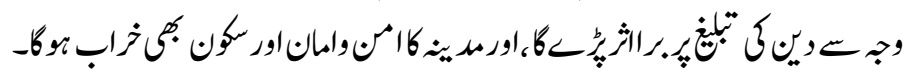

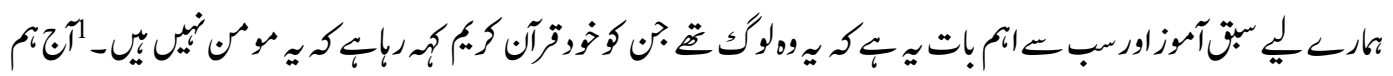

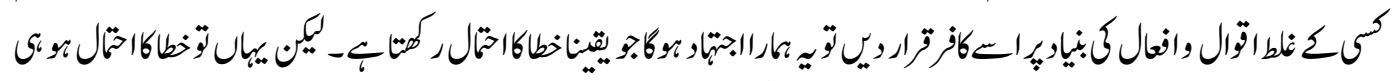

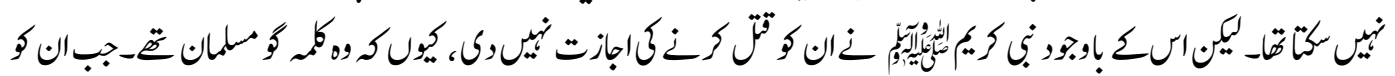

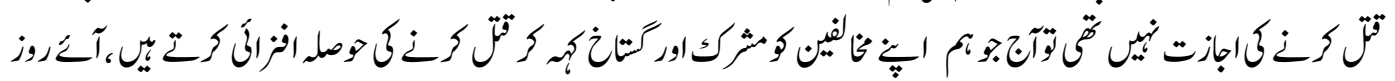

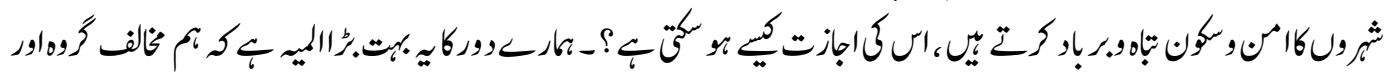

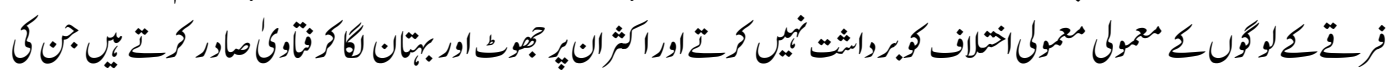

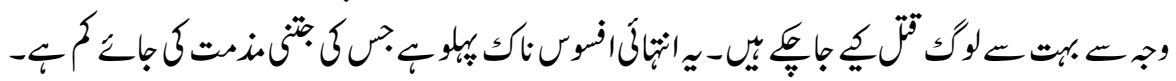

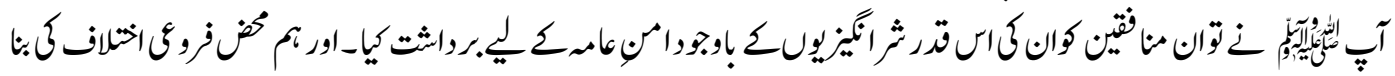

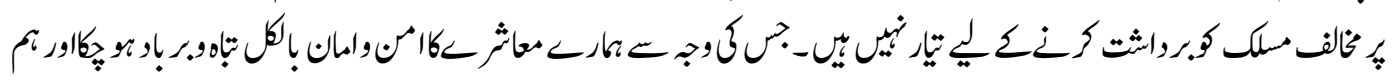

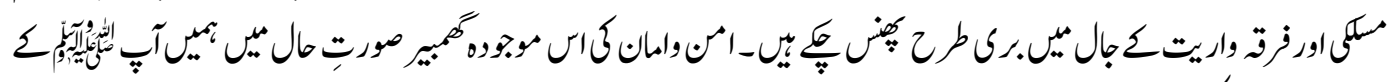

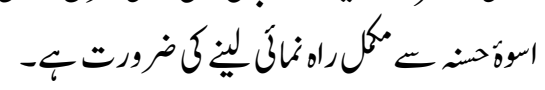

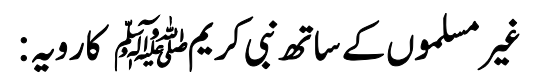

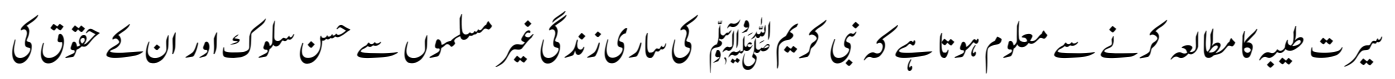

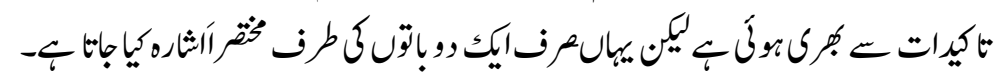

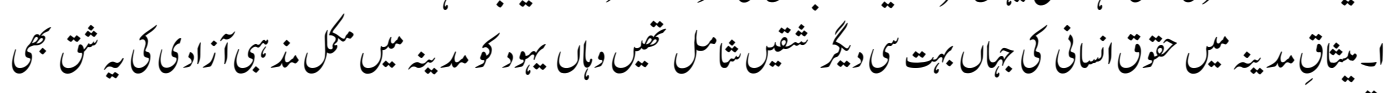

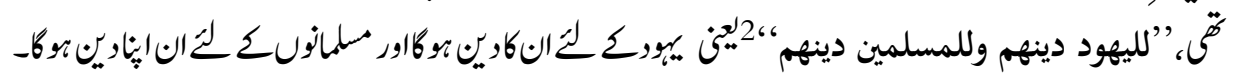

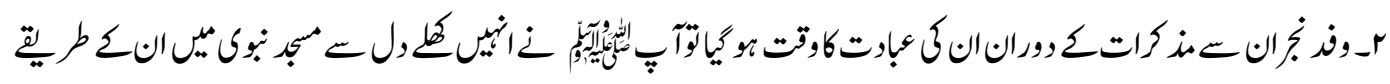

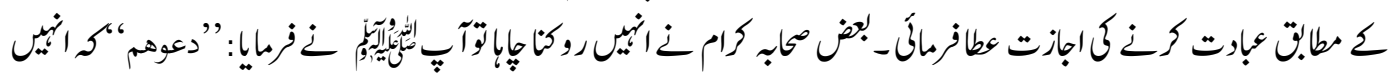

${ }^{2}$ Hamidullah, Dr. Muhammad, The First Written Constitution in the World, (Lahore: Sheikh Muhammad Ashraf,1975), p:24

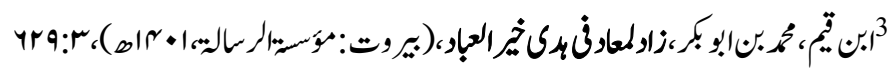




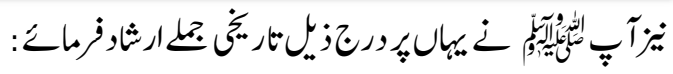

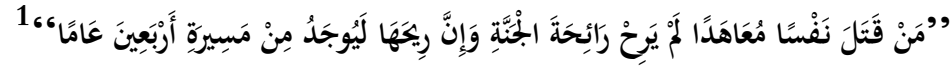

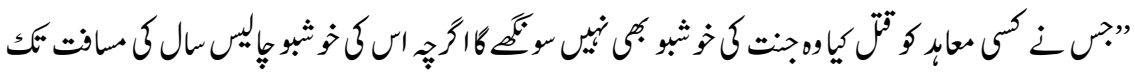
"द

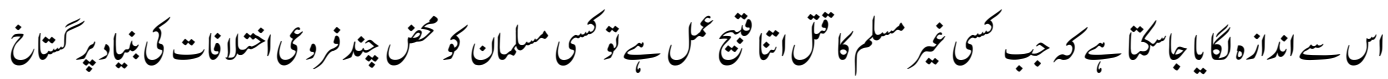

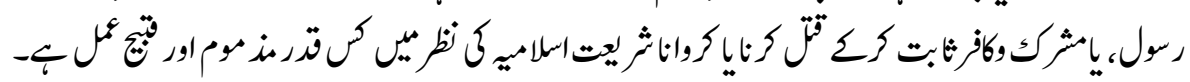

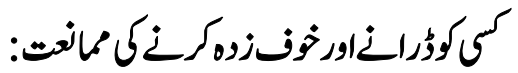

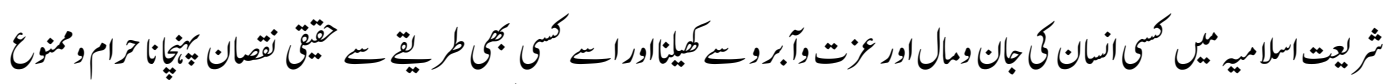

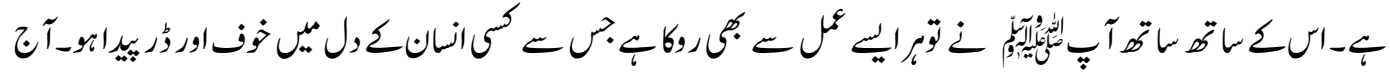

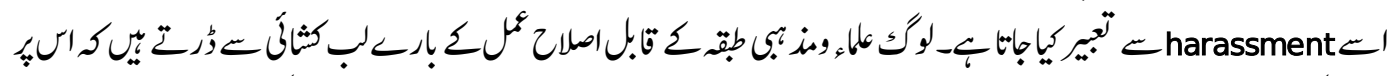

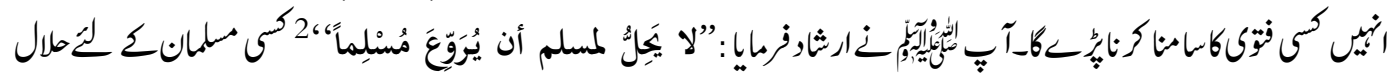

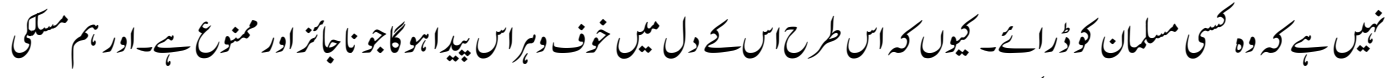

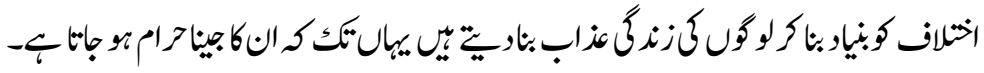

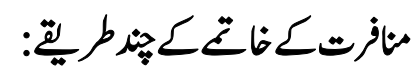

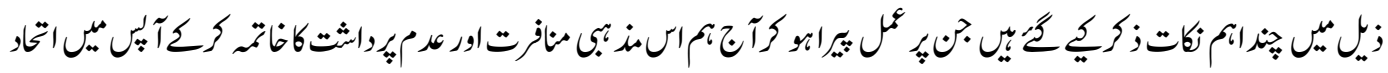

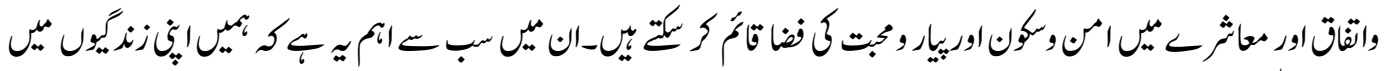

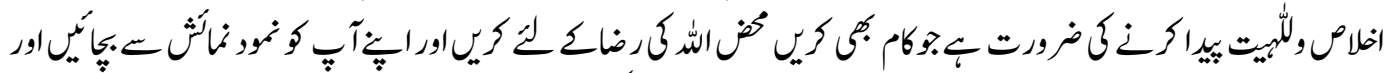

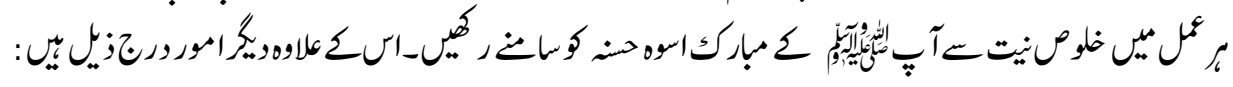

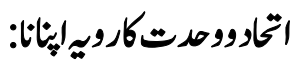

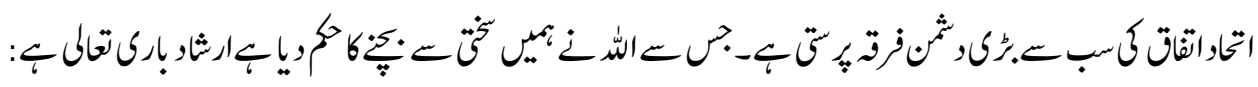

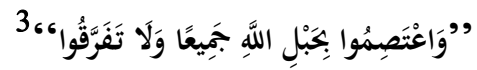

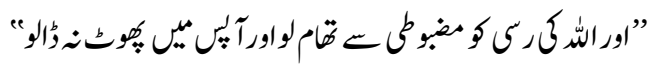

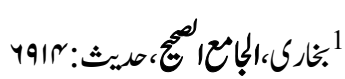

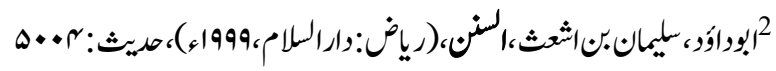

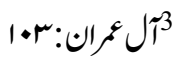




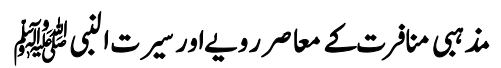

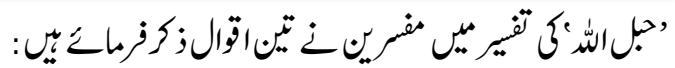

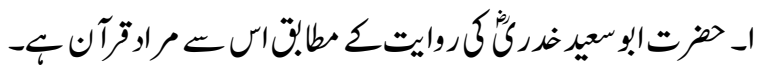

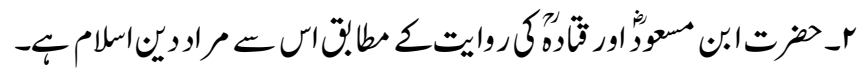

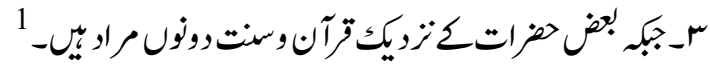

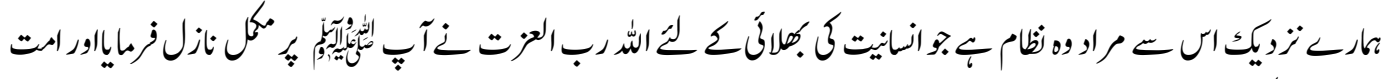

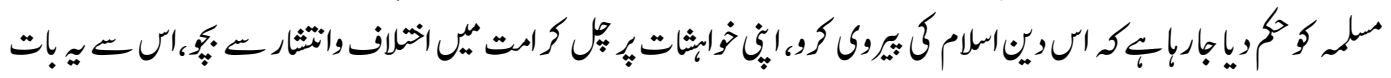

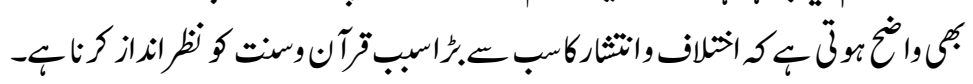

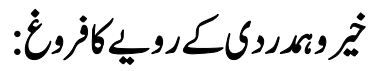

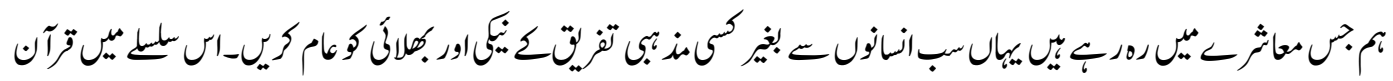

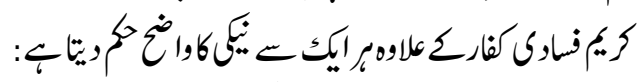

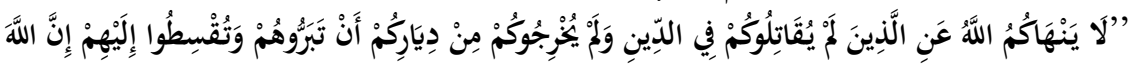

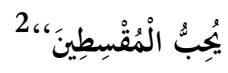

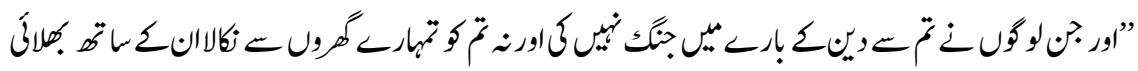

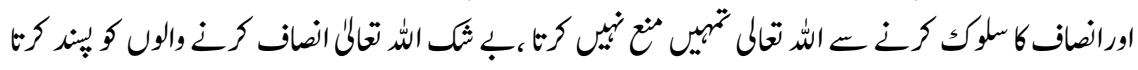

$$
\begin{aligned}
& \text { "द }
\end{aligned}
$$

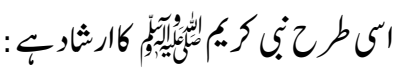

$$
\begin{aligned}
& \text { "الدينُ النَّصيحة،، } 3
\end{aligned}
$$

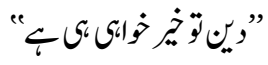

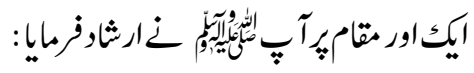

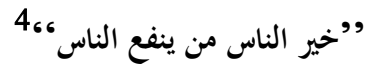

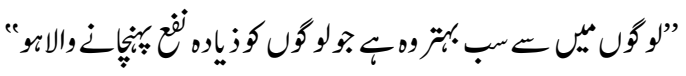

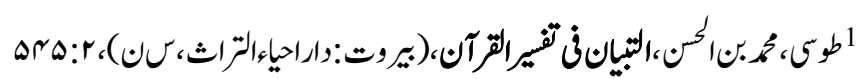

$$
\begin{aligned}
& \text { A. }
\end{aligned}
$$

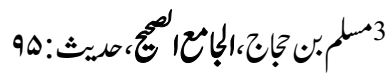

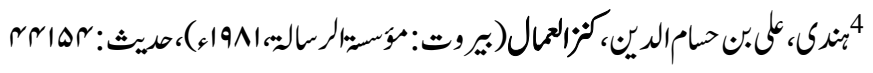




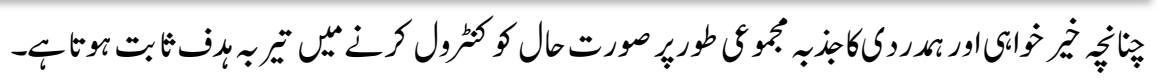

كخالفس عدل

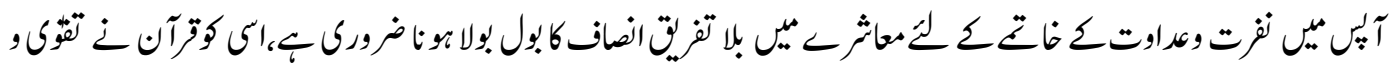

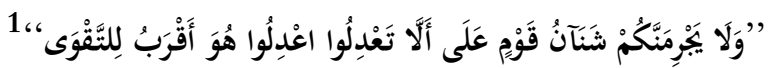

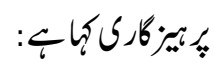

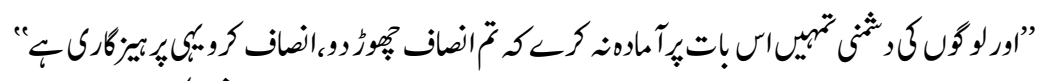

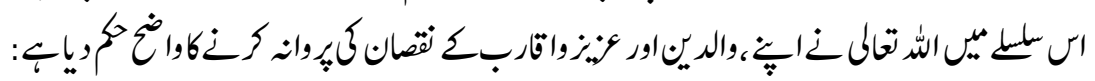

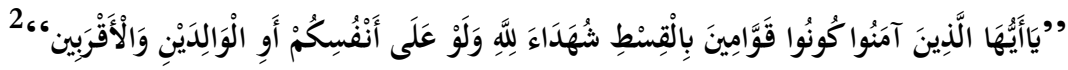

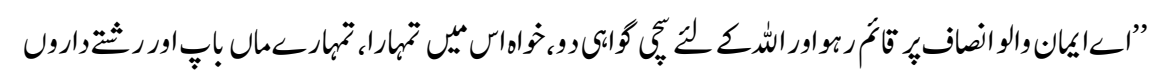

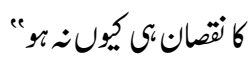

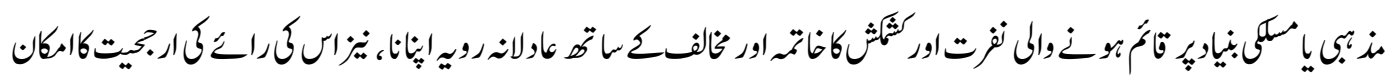

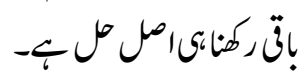

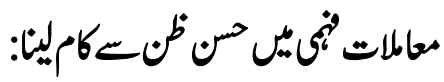

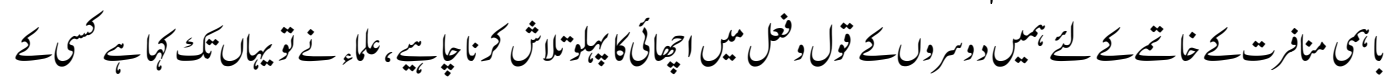

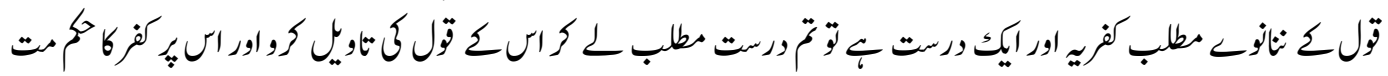

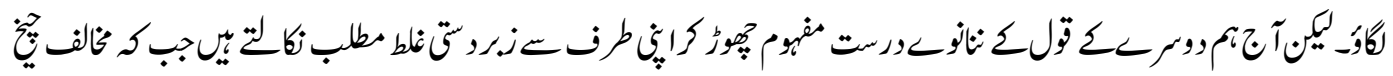

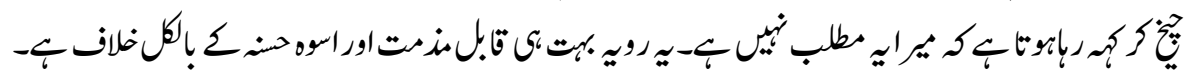

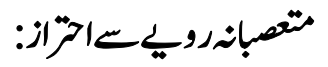

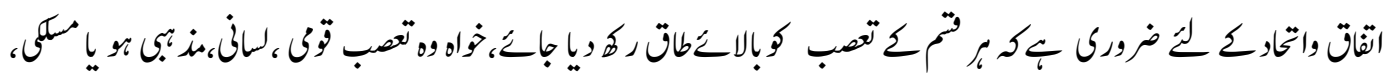

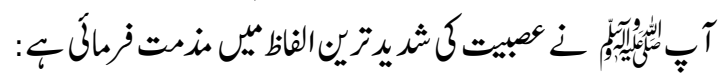

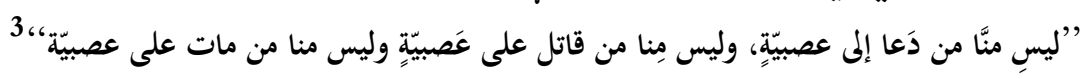

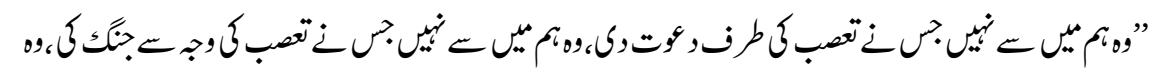




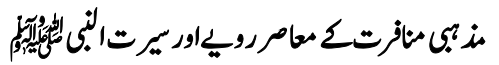

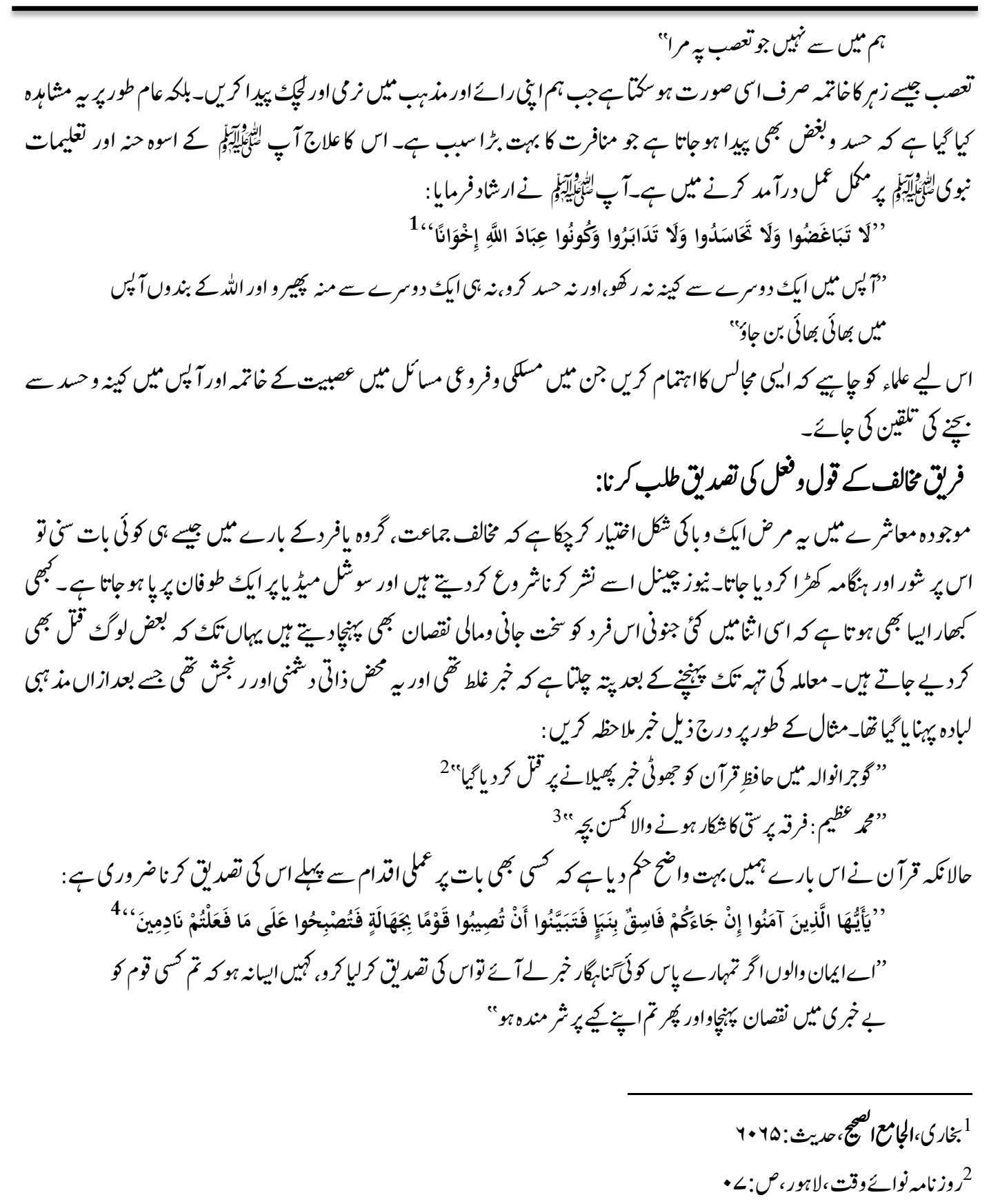

${ }^{3}$ https://asrehazir.com/msadiqqasmi-5/, (Accessed Dec 27, 2019 at 09:30 AM) 


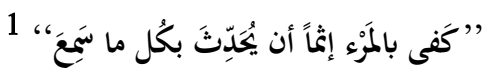

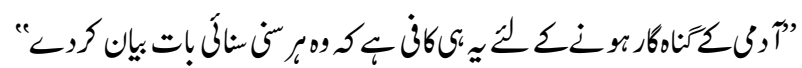

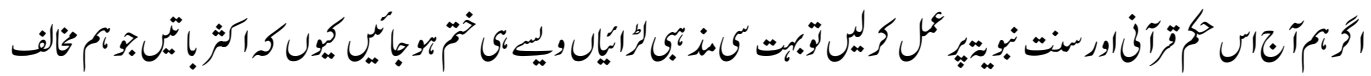

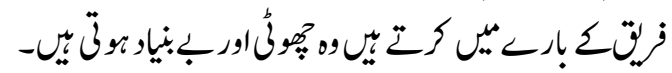

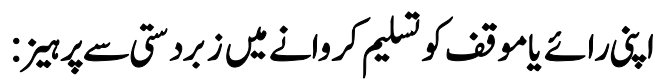

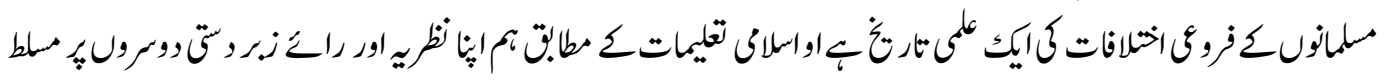

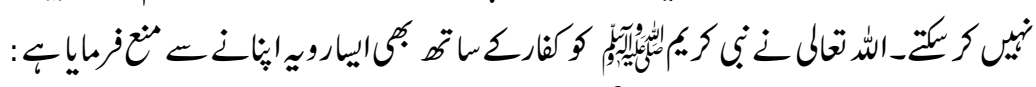

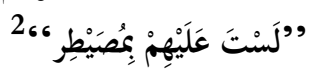

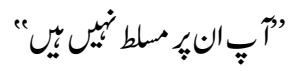
ايكساورمقاميرارشارفايا:

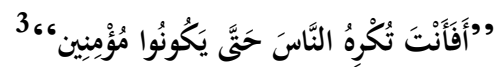

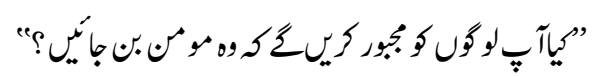

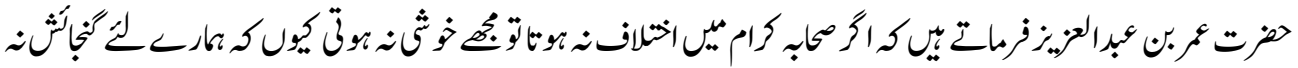

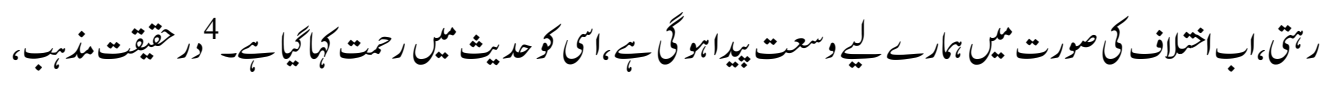

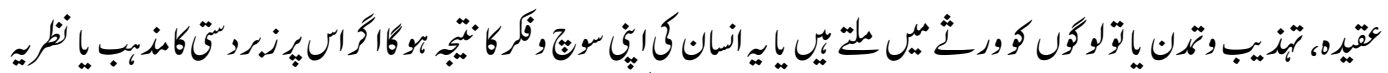

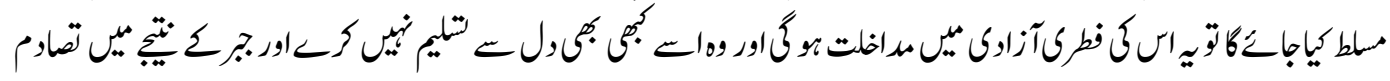

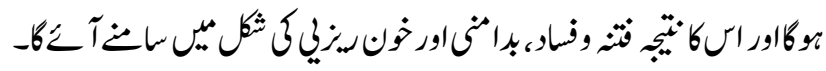

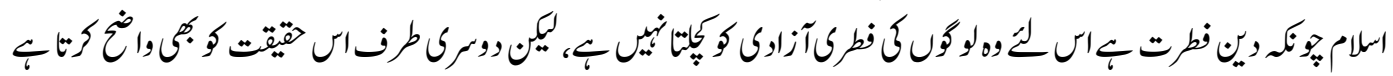

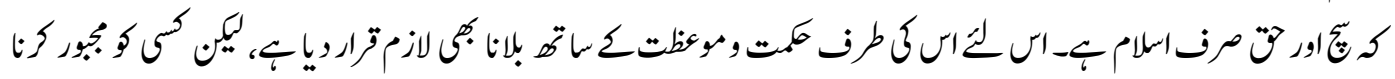

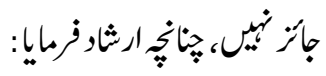

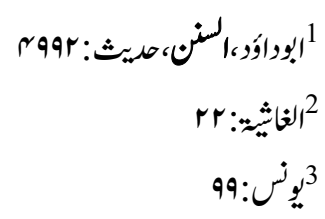

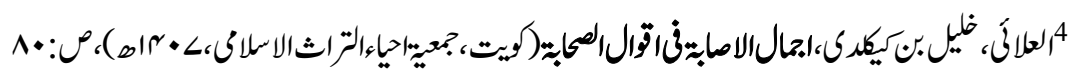




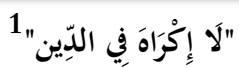

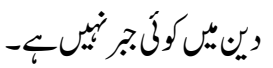

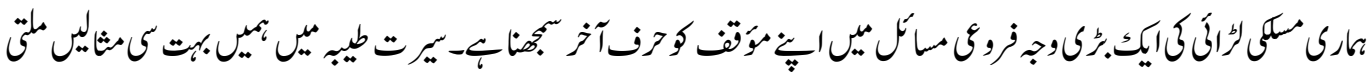

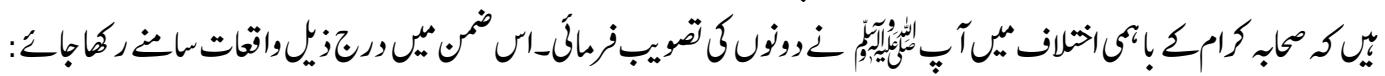

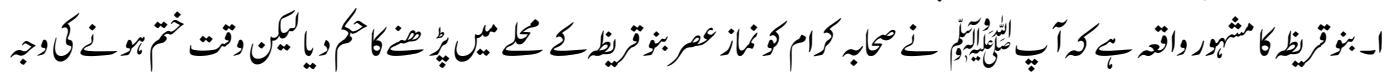

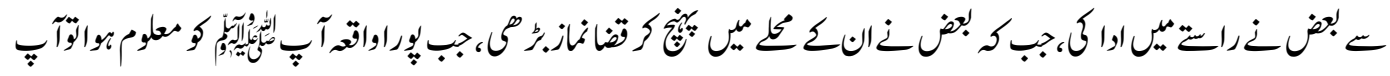
2

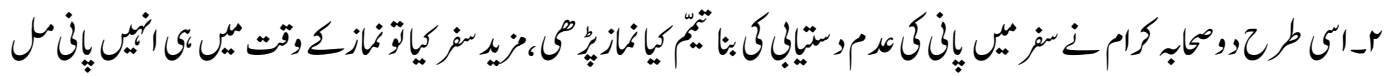

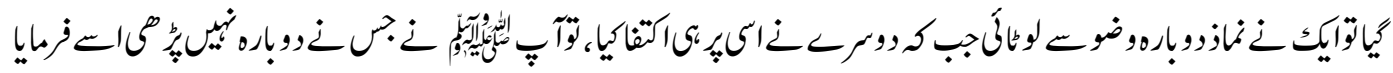

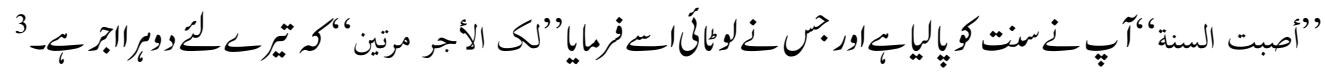

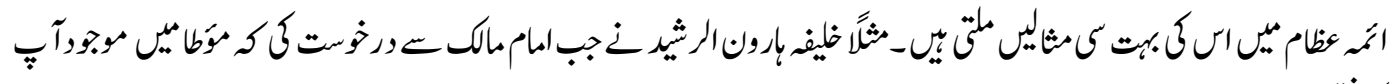

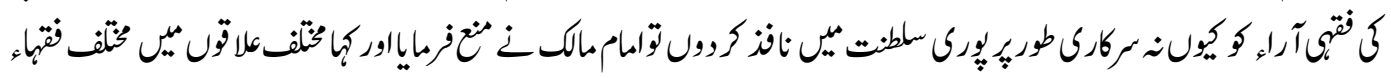

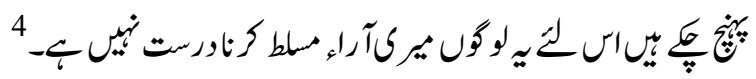

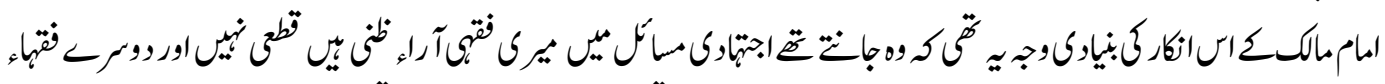

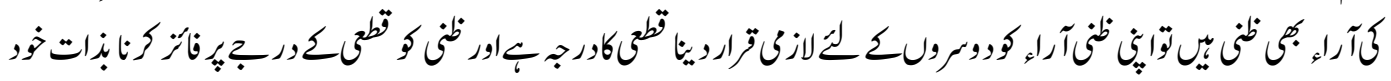

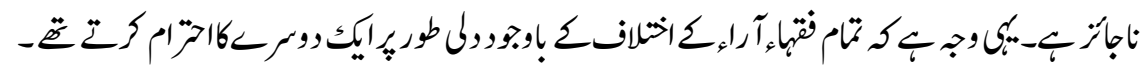

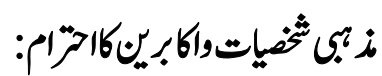

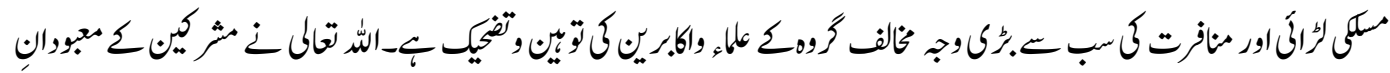

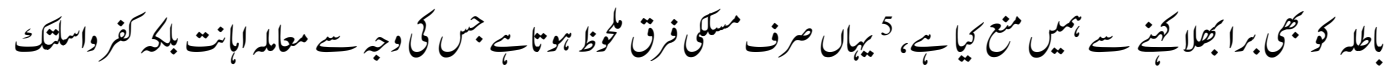

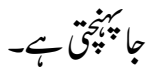

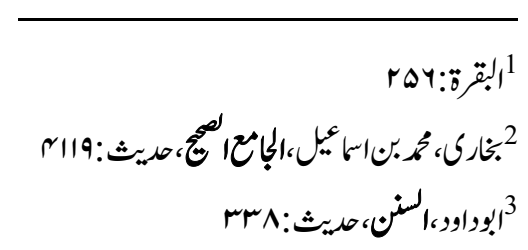

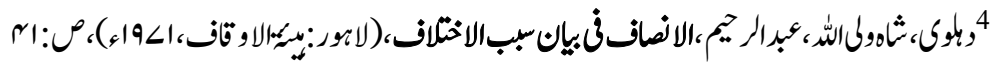

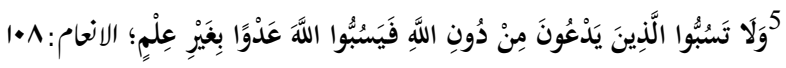




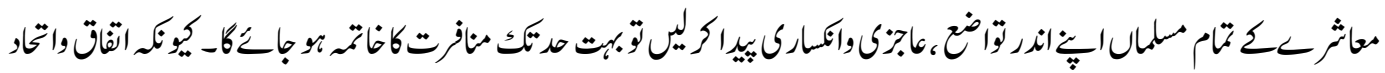

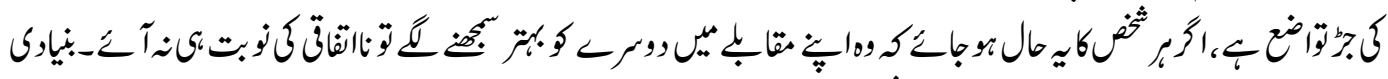

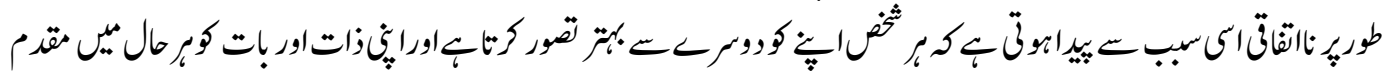

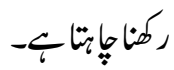

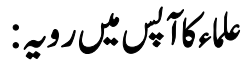

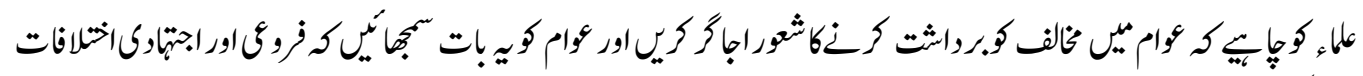

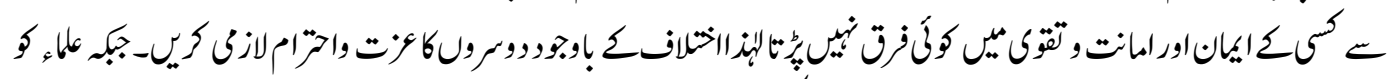

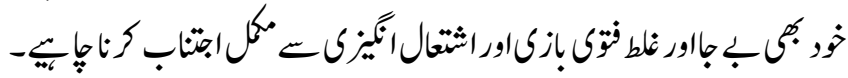
غلوساتزثاب:

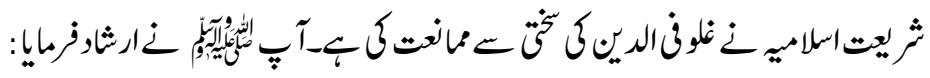

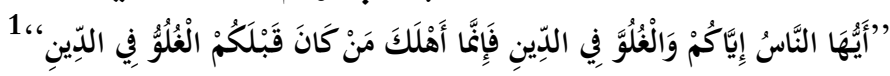

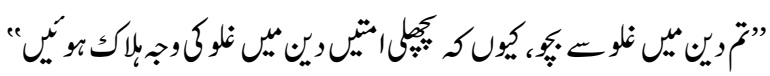

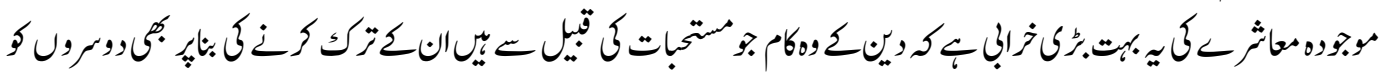

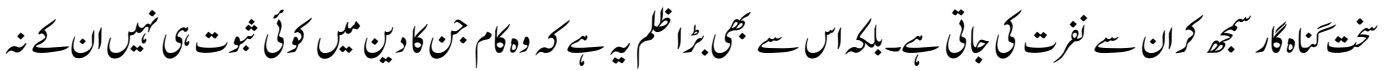

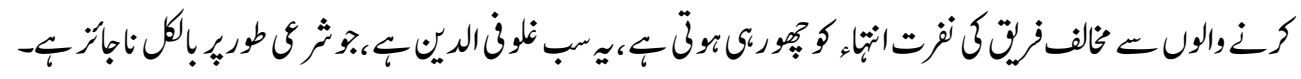
خلاصم.كث:

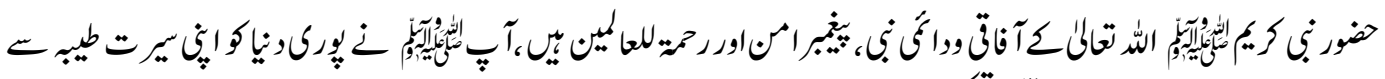

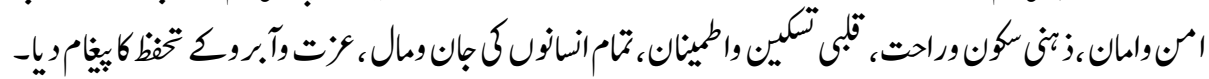

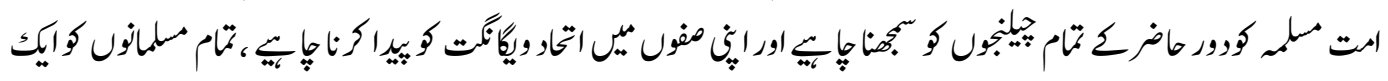

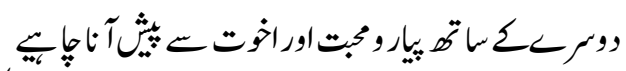

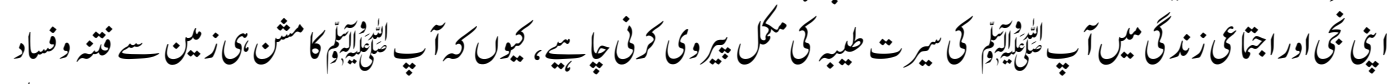

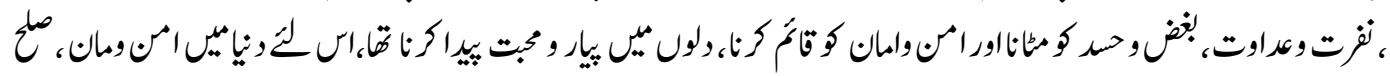

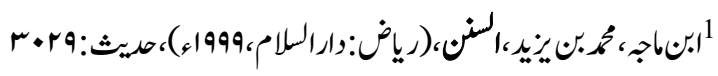




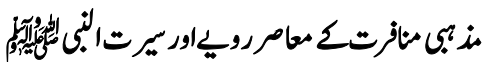

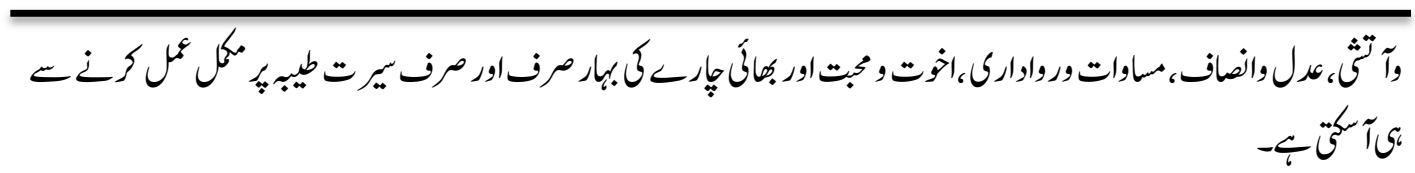

(a) 2019 by the author, this article is an open access article distributed Under the terms and conditions of the Creative Commons Attribution (CC BY) (http://creativecommons.org/licenses/by/4.0/) 